which is required in high concentration by $L$. helveticus and also L. arabinosus and Streptococcus lactis (Pollack and Lindner ${ }^{3}$, and our own unpublished observations). our main difficulty, for example, in the microbiological assay of nicotinic acid has been to free the peptone of its nicotinic acid without at the same time removing this unknown factor.

Chattaway, Happold and Sandford ${ }^{4}$ have described a 'synthetic' medium using hydrolysed casein in place of peptone for the assay of riboflavin, and have stressed the need for $\mathrm{Ca}$. to be present. This medium, however, suffers from the fundamental defect that it contains no sodium acetate, and is therefore insufficiently buffered (Stokes and Martin ${ }^{5}$ and our own unpublished observations). In so far as calcium chloride is a very much less satisfactory buffer than sodium acetate it fails to maintain the desirable $p \mathrm{H}$ for optimal growth and acid production-if a suitable amount of sodium acetate be present in the medium the presence of $\mathrm{Ca}$ ions has no effect one way or the other on the titrations.

Further evidence for the inadequacy of the medium used by Chattaway et al. is shown (1) by the fact that they were unable to obtain satisfactory values for the riboflavin content of certain foodstuffs; (2) the fact that its sensitivity in response to added riboflavin is very low $-0.1-0.8 \mu \mathrm{gm} . / 10 \mathrm{ml}$. medium, cf. Fig. 1 (Chattaway et al.) with a maximum titration of $6 \mathrm{ml} . \mathrm{N} / 10 \mathrm{NaOH}$. With the Snell and Strong medium the range of riboflavin used varies from 0.05 to $0.2 \mu \mathrm{gm}$. and the maximum point is reached at $0.25 \mu \mathrm{gm}$. The titration value here is between 17 and $18 \mathrm{ml}$. $N / 10 \mathrm{NaOH} / 10 \mathrm{ml}$. of medium.

Finally we would point out that it can scarcely be mere coincidence that assays carried out by the microbiological, fluorometric and biological methods on the same material all agree within experimental error (Barton-Wright and Booth ${ }^{1}$, Copping ${ }^{6}$ ). This agreement has since been extended to mixed diets, the results of which will shortly be published.

$$
\begin{aligned}
& \text { E. Barton-Wright. } \\
& \text { R. Gordon Booth. }
\end{aligned}
$$

Cereals Research Station,

Ministry of Food,

Old London Road, St. Albans.

Sept. 18.

${ }^{2}$ Barton-Wright, E. C., and Booth, R. G., Biochem. J., 37, 25 (1943). s Saeli, E. E., and Wright, L. D., J. Biol. Chem., 139, 675 (1941). Pollack, M. A., and Lindner, M., J. Biol. Chem., 147, 183 (1943). CChattaway, F. W., Happold, Fi. C., and Sandford, M., Biochem. J. 87,298 (1943).

'Stokes, J. L., and Martin, B. B., J. Biol. Chem., 147, 483 (1943). 'Copping, A. M., Biochem. J., 37, 12 (1943).

\section{An Alumina Hydrogel}

Sous of hydrous alumina are generally prepared either by the hydrolysis of aluminium acetate solutions, or by the peptization of freshly precipitated hydrous alumina. Such sols are converted to gels by the addition of a suitable small amount of electrolyte, and the gels so formed are thixotropic at concontrations so low as 1 per cent $\mathrm{Al}_{2} \mathrm{O}_{3}$.

Pavelka ${ }^{2}$ prepared an alumina sol by the addition of ammonia to an aluminium salt in the presence of boric acid. The following discussion shows how an alumina gel may be formed in the presence of boric acid without the addition of ammonia. The gel is formed simply by cooling a sol of suitable composition, as in the typical preparation of an organic jelly.
In the course of the colorimetric determination of silica in alumina, the alumina was brought into solution by fusion with a mixture containing 2 parts of sodium potassium carbonate to 1 part of anhydrous borax. The melt was afterwards extracted with water, and the aqueous solutions, under certain conditions of concentration and $p \mathrm{H}$, were found, on standing, to be converted into gels which exhibited, to a slight extent, the phenomenon of thixotropy.

If a solution containing $4.45 \mathrm{gm}$. of $\mathrm{Al}_{2} \mathrm{O}_{3}$ and $17.8 \mathrm{gm}$. of fusion mixture in $100 \mathrm{ml}$. was allowed to stand in the cold, it was converted into a gel which, on shaking, was transformed to a viscous liquid. More concentrated solutions (5 gm. $\mathrm{Al}_{2} \mathrm{O}_{3}$ and $20 \mathrm{gm}$. of fusion mixture in $100 \mathrm{ml}$.) formed a brittle gel which became pasty on stirring. If left undisturbed, these gels soon regained their original firmness.

The sol-gel transformation is reversible, since, on warming, the gels were converted into sols. The time required for the cooled sols to be reconverted into gels was found to depend on their concentration. If the most concentrated sol was allowed to stand, a cloudiness and increase in viscosity was observed after half an hour, and the mixture set to a firm gel after an hour. If this sol was diluted to $2 \cdot 5$ times its original volume, so that it contained $2 \mathrm{gm}$. of $\mathrm{Al}_{2} \mathrm{O}_{3}$ and $8 \mathrm{gm}$. of fusion mixture in $100 \mathrm{ml}$., the cloudiness appeared after three hours and gel formation was complete after forty hours; if the solution was further diluted so as to contain $1.33 \mathrm{gm}$. of $\mathrm{Al}_{2} \mathrm{O}_{3}$ and $5.33 \mathrm{gm}$. of fusion mixture in $100 \mathrm{ml}$., the cloudiness appeared after twenty-four hours and a gel was formed after four days. All these gels suffered a marked decrease in viscosity on shaking.

In the most concentrated solutions a deposition of boric acid occurred, but this did not prevent gel formation.

The stability of these concentrated gels to acid was also investigated by acidifying the sol with nitric acid and testing its $p H$ by means of the glass electrode before gel formation commenced. In this way it was found that a sol with $p \mathrm{H}$ so low as $2 \cdot 4$ was converted into a gel in the usual way. Addition of more $8 \mathrm{~N}$ nitric acid brought about the permanent destruction of the gel.

Department of Chemistry,

University of Western Australia.

1 Freundlich and Bircumshaw, Kolloid-Z., 40, 19 (1926) ; Freundlich,

46, 294 (1928).

\section{Production of Freshwater Fish in Palestine}

IN his article on the "Freshwater Fisheries in the British Colonial Empire"', Dr. E. B. Worthington stresses the importance of freshwater fish production, but points out that in many parts of the Empire the fresh waters are being neglected. Taking Lake Victoria as an example, he estimates the production of fish in this great tropical lake to be only about $1.4 \mathrm{lb}$. per acre per year. This "ridiculously small" figure he compares with the North Sea which produces about $15 \mathrm{lb}$. per acre per year, and explains that in Lake Victoria only the fish of the inshore waters are taken, while the main mass of the water, 26,800 square miles in area, but less than $270 \mathrm{ft}$. in depth, is left undeveloped and unexploited.

It is interesting to compare these figures with those 